\title{
Creating green culturally responsive intelligent buildings: Socio-cultural and environmental influences
}

\begin{abstract}
Today, the concept of green and sustainably built environments is considered one of the main targets of various governmental sectors and policy-makers in the creation of a better environment for the population. However, a critical task consists in debating the significance of sustainability and a green built environment before the initiation of any green project. Accordingly, this article suggests the fundamental role of sustainability in better built environments as well as indicating an omission within green and sustainable design development arising because of a lack of consideration of the traditional, cultural and regional values of users. Focus is made on smart housing as an intelligent building design development that is highly interrelated with sustainable issues, highlighting the lack of a deep consideration of the cultural values of users for ensuring socio-cultural sustainability. The article also draws attention to the profound vernacular features of vernacular settlements, which are substantially in harmony with the regional and cultural values of a region. The context is limited to the Malay experience, identifying the vernacular features of the functional spaces of a Malay vernacular settlement for utilization in a smart housing design within Malaysia with a view to making them culturally responsive. At the same time, this article proposes the concept of green culturally responsive intelligent building design development based on the integration of vernacular architectural features into intelligent buildings in order to enhance the quality of life.
\end{abstract}

